\title{
Connexions entre el ball i la prostitució en la tardor medieval: fembres pecadrius, reis arlots i çabies
}

\section{Connections between dance and prostitution in medieval autumn: sinful females, King of Harlots and çabies}

\author{
RAÜl SANCHIS FRANCÉS \\ raul.sanfra@gmail.com \\ LAREM i ICONODANSA \\ Universitat Rovira i Virgili
}

\begin{abstract}
Resum: En aquest estudi es constaten les estretes relacions existents durant la tardor medieval entre les fembres pecadrius i la pràctica del ball: per una banda, als ravals i els prostíbuls, controlats algun temps per la figura del rei Arlot, i per l'altra, a l'entorn de la cort, sota el redós de les classes dirigents. A més, s'hi analitzen impostos com la tarquena o tarchana (tarcón en castellà), que gravava les activitats de les çabies o sabies (prostitutes musulmanes) i les intervencions musicals dels joglars en les noces i les sambres del col lectiu sarraí.
\end{abstract}

Paraules clau: ball, prostitutes, rei Arlot, çabies, tarquena, edat mitjana

\begin{abstract}
This study shows the close relationship between the sinful females (fembres pecadrius) and the practice of dance during the medieval autumn: on the one hand, in the slums and brothels, controlled by the figure of King of Harlots for some time, and on the other, in the Court, under the shelter of the ruling classes. In addition, it analyses impositions such as the tarquena or tarchana (also tarcon, in Castilian), which taxed the activities of the çabies or sabies (Muslim prostitutes) and the musical interventions of the minstrels at weddings and zambras of the Saracen collective.
\end{abstract}

Keywords: dance, prostitutes, king of Harlots, çabies (Muslim Prostitutes), tarquena (Tax), Middle Ages

\footnotetext{
*Aquest treball forma part de les investigacions realitzades en el marc de tres projectes de recerca, dos en grups de la Universitat Rovira i Virgili de Tarragona: LAiREM (GRC 2017 SGR 1514; AGAUR-Generalitat de Catalunya) i ICONODANSA (HAR2017-85625-P, Ministerio de Ciencia, Innovación y Universidades del Gobierno de España), i un altre al redós del grup de treball «Biografies marginals» de la Universitat de València (PGC2018-097011-B-I00, finanç̧at pel mateix ministeri governamental). L'article que publiquem ací és una versió revisada del capítol 6.4 de la nostra tesi doctoral (Sanchis Francés 2019), que vam presentar el 15 d’octubre de 2020 al Congrés Internacional virtual «Proscrits, marginats i minories a la Corona d'Aragó (ss. XV-XVIII). Textos i vides» [«Les fembres pecadrius i el ballls; en línia: https://youtu. be/vO0Dnl--rhw].
}

DATA PRESENTACIÓ: 11/09/2020 ACCEPTACIÓ: 01/10/2020 · PUBLICACIÓ: 10/12/2020 
Raül Sanchis Francés. Connexions entre el ball i la prostitució en la tardor medieval: fembres pecadrius, reis arlots i çabies

\section{Introducció}

La prostitució era un fenomen d'una dimensió rellevant a la societat medieval occidental. ${ }^{1} \mathrm{~A}$ la València del segle XIII en endavant, en consonància amb altres indrets d'arreu d'Europa, hi havia una -doble- moral basada en la visió agustiniana que considerava les prostitutes un mal necessari que evitava mals majors; ${ }^{2}$ una ètica bipolar a mig camí entre la consideració pecaminosa i reprovable, promulgada sobretot pels estaments eclesiàstics, i la permissivitat, fruit d'un procés d'institucionalització conduit per les autoritats com a mecanisme de control de la població i caracteritzat, a més a més, per l’ànim recaptatori (FIG. 1).

Les meretrius esdevenien una vàlvula d'escapament que permetia contenir les conductes sexuals considerades inapropiades i perilloses i, per tant, censurables. Durant el darrer període medieval i bona part de l'edat moderna, la ciutat de València fou famosa a tot Europa pel seu prostíbul: la Pobla de les fembres pecadrius o de les auls fembres, el Públich o, senzillament, la Pobla (FIG. 2). A més dels centenars de prostitutes documentades que exercien en aquest bordell, tota una munió de dones -fembres escuseres o fembres errades- vivien o complementaven el seus ingressos gràcies al sexe clandestí. ${ }^{3}$ S'establien als ravals de la ciutat o en tavernes i hostals. Per la insistència amb què s'emetien directrius punitives, sembla que l'objectiu de les autoritats per eradicar-les no acabava de quallar mai, ja fora per la dificultat d'eliminar el fenomen o, tal vegada, pels interessos econòmics furtius en joc. Hi havia putanes cristianes, mores, jueves i de les més diverses procedències. Sovint,

1 Benito Julià (2018: 32-42) aporta un seguit de referències bibliogràfiques sobre l'estat de la qüestió dels estudis dedicats a la prostitució, especialment per al període medieval. A València, és un clàssic el monogràfic Picaronas y alcabuetas o la mancebia de Valencia de Carboneres (1876). Uns anys abans, però, Boix (1855: cap. XXXVI) ja havia dedicat un capítol a la «Mancebía de Valencia» en una de les seues obres. Més endavant, Sanchis Sivera (1935) acreix la informació proporcionada pels anteriors autors en una sèrie d'articles publicats entre 1932 i 1935 a la revista Anales del centro de cultura valenciana sobre la «Vida íntima de los valencianos en la época foral». Més recentment, podem destacar altres treballs que enquadren aspectes generals i particulars de la prostitució a la ciutat i el regne de València durant l'edat mitjana i l'època moderna (Cabezuelo Pliego 2019; Grau Monserrat 1978; Graullera Sanz 1990; 2006; Guillot Aliaga 2015; Narbona Vizcaíno 2006; Pérez García 1991; Peris 1990; Rangel López 2008; Viciano 2005; Vidal Gavidia 2001...).

2 La idea -força coneguda- del mal menor de sant Agustí d'Hipona (354-430), que té com a màxima la dita «tanqueu els bordells i la luxúria ho envairà tot» (De Ordine, II.IV, 2), és un topos renovat i propagat al llarg de la història per tot un seguit de teòlegs i predicadors, especialment durant la baixa edat mitjana: Tomàs de Chobham, Tomàs d'Aquino, Francesc Eiximenis, Vicent Ferrer, etc. Vegeu, per exemple, Benito Julià (2018: esp. 71-80).

3 La terminologia associada a la prostitució que podem trobar a les fonts arxivístiques i literàries medievals i modernes és riquíssima. Segons Pérez García (1991: 19-20), per exemple, mentre les meretrius del bordell sovint s'anomenen fembres o dones de cadira-per raons evidents-, aquelles que practiquen el sexe clandestí al carrer, a les tavernes o a les cases particulars, s'anomenen fembres de vall, fembres de vila, dones dissolutes, fembres cantoneres, fembres de vora mur o fembres escuseres. També segons Pérez García, als documents de la Cancelleria i als dels governs locals, en què no es distingeix la prostitució legal de la il legal, es pot establir una gradació de tres nivells que en delimita la tipologia terminològica: mitjançant una mena de llenguatge tècnic (dones de guany, dones que viuen del quest), de rebuig moral (dona deshonesta, dona mundana, fembra pública, dona de mal viure, de falta de normalitat, dones errades), i, finalment, de condemna religiosa (fembra àvol de son cos, fembra peccadriu). En la parla vulgar destaquen els insults o improperis per a referir-se a les dones marginades: puta, bagassa, vil, gossa, perra, etc. Un cas particular, com veurem més tard, és el de les çabies o sabies mores. 
Raül Sanchis Francés. Connexions entre el ball i la prostitució en la tardor medieval: fembres pecadrius, reis arlots i çabies

per evitar prostituir-se a la població natal, on eren conegudes, les meuques emigraven a les ciutats més poblades, sobretot d'altres regnes. A les zones rurals el fenomen també era ben present, però és més difícil rastrejar-lo per la falta de documentació. ${ }^{4}$

En termes generals, durant la baixa edat mitjana, la prostitució era tolerada sempre que s'exercira als bordells legitimats per les autoritats locals i les disposicions reials. Almenys fins al segle $\mathrm{xV}$, no era considerada un delicte tipificat com a tal, raó per la qual els furs no la regulen, tot $\mathrm{i}$ que n'assumeixen l'existència. ${ }^{5}$ Això no vol dir, per descomptat, que fora ben vista. De fet, era reprovada insistentment pels moralistes, els predicadors i els membres més puritans de la societat. La seua pràctica estava envoltada, sobretot en l'àmbit clandestí, d'un món íntimament vinculat a la violència, la tafureria, els excessos i l'explotació sexual. En definitiva, un univers dominat per la gent rufianesca o «d'àvol art» que entrava en contacte amb totes les capes masculines de la societat que sol licitaven els seus serveis. Però el més rellevant per a la nostra investigació és que almenys una part d'aquestes prostitutes feien servir el ball i els espectacles de caire eròtic per atreure clients, ja foren pagesos, ciutadans, nobles, clergues o joglars (FIG. 3).

\title{
2. Les fembres pecadrius i el ball
}

El fet que l'Església considerara impures les prostitutes venia determinat per la deshonesta utilització que feien del seu cos, per la gestualitat que exhibien i pel mercadeig d'allò que era considerat un do de Déu. De fet, arguments semblants s'aprofitaren per a condemnar qualsevol professió que fera servir el cos com a mitjà d'expressió, com ara la de joglar:

\begin{abstract}
La duresa del blasme catòlic contra el joglar radicava en el fet que eren portadors d'unes tècniques i unes habilitats basades en el cos i la seva expressió, i ja sabem l'estranya relació que el cristianisme ha mantingut sempre amb la corporeitat, amb tota mena de tabús, repressions i ocultacions. Les invectives contra el joglar se centraven sobretot com a expositor de sí mateix, com a ser que fa espectacle del seu cos. Per això se l'acusa, com a la prostituta, de fer del seu cos (un do de Déu) objecte de mercadeig i d'exhibició [...] Però aquestes consideracions comencen a posar-se en qüestió ja al tombant del segle xII, quan el joglar s’ha convertit en la viva veu de la cultura medieval i en el personatge amb major mobilitat geogràfica i social de l'edat mitjana (Massip 2012: 318).
\end{abstract}

Tanmateix, sembla que un bon grapat de religiosos acudien als prostibuls, als bordells clandestins o als ravals buscant satisfaccions prohibides, tal com ho demostren, de manera directa o indirecta,

\footnotetext{
4 Per exemple, a València, en el període temporal estudiat per Peris (1990: 191), de 1367 a 1399, només el 7 \% de les prostitutes documentades eren valencianes, front al 53 \% que procedia de Castella. La resta venien d'Aragó, Navarra, Catalunya, Mallorca, Itàlia, França, Portugal i Grècia.

5 Vegeu les consideracions que fa Narbona Vizcaíno (2006: 236) sobre aquest tema i la informació que proporciona sobre la modificació introduïda pel rei Martí, a instància dels braços eclesiàstic i reial, de la rúbrica jaumina De crims durant les Corts de València de 1403: «Contra alcavots qui freqüenten en bordells o tavernes ab fembres [...]».
} 
Raül Sanchis Francés. Connexions entre el ball i la prostitució en la tardor medieval: fembres pecadrius, reis arlots i çabies

diverses disposicions sinodals. En aquesta direcció, cal ressaltar que, només vint anys després de la conquesta cristiana de la ciutat de València, el 1258, trobem una de les primeres notícies sobre dansa al nou regne de València. Aquell any, el bisbe Andreu d'Albalat presideix el segon sínode diocesà que se celebrà a la ciutat. En una de les disposicions es prohibeix als clergues entrar a les tavernes $i$ assistir als espectacles $i$ als balls que oferien determinades dones: ${ }^{6}$

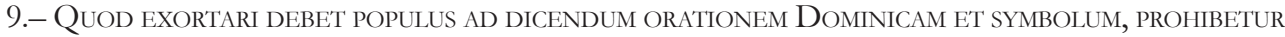
LUdus AD TAXILlos ET DE UIGILIIS ET EXCESSIBUS, QUI IBIDEM FIUNT, ET DE MORIBUS [...] Item probibemus uniuersis clericis ludere cum taxillis, interesse spectaculis uel coreis mulierum, intrare tabernas causa potandi, uel sine socio intrare domos mulierum suspectarum aut discurrere per uicos et plateas, et ire cotidie ad mercata, cum non subest causa [...] (Pérez de Heredia y Valle 1994: 93-94). ${ }^{7}$
\end{abstract}

Tot apunta que aquestes dones eren prostitutes o joglaresses que representaven balls pujats de to i que el lloc d'escenificació dels espectacles no devia ser precisament un espai sagrat. Però ens interessa més remarcar la denúncia en si mateixa i els protagonistes, pels caràcters negatiu i viciós que s'atribueix al ball-també als jocs, els espectacles, etc.-i a la dona, incitadora dels pecats luxuriosos que cometien els clergues. No hem d'oblidar l'estreta relació que s'estableix en el pensament religiós imperant a l'època entre la feminitat i el mal, entre la dona i la figura del dimoni (Toldrà 2011).

Més tard, sota el regnat de Jaume II el Just, unes extenses ordenacions festives de 1326 promulgades pels jurats de la ciutat prohibien, entre moltes altres coses, que «nenguna fembra pecadriu no gos ballar fora lo loch lo qual los és asignat per estan». ${ }^{8} \mathrm{El}$ preu de la multa en cas d'incompliment era de deu sous per cadascuna de les vegades que es transgredia l'ordenament establert. En cas de no

6 Fem servir les cursives en aquest fragment textual i els següents per remarcar aquells paraules clau que considerem rellevants en relació amb el tema que estem tractant.

7 Sínode de València, 22 d'octubre de 1258, presidit pel bisbe Andreu d'Albalat, constitució 9 (Sanchis Francés 2019: II, doc. 1258.1). El mateix text el recull el vicari general de Barcelona Francesc Rufac en una compilació de cànons dels sínodes diocesans barcelonins anteriors a 1354: «Item, prohibemus uniuersis clericis ludere cum taxillis nec interesse spectaculis uel coreis mulierum, nec intrare tabernas causa potandi uel sine socio intrare domos mulierum suspectarum aut discurrere per uicos et plateas, nec ire cotidie ad mercata cum non subest causa, nec suspensioni latronum nec combustioni etiam aliquorum nec sanguinis effusioni intersint» (Hillgarth \& Silano 1984: 110). Una bona part dels textos de Rufac provenen de la Summa Septem Sacramentorum de l'arquebisbe de Tarragona Pere d'Albalat, germà d'Andreu, el susdit bisbe de València. Per a més informació sobre aquestes relacions, vegeu Sanchis Francés (2019: I, 311, nota 749). També trobem un text semblant al Livre Rouge, un recull de constitucions sinodals del capítol metropolità de la diòcesi occitana d'Aush dels segles XIII i XIV: «DE ORDINATIONE CLERICORUM ET HORIS DICENDIS ET DE ORDINATIONE ALTARIUM. Ludere cum deciis, aut alio modo illicito, ut peccunia aut res aliqua admittatur, interesse lacrimosis spectaculis vel ludis inhonestis, coreis mulierum assistere vel ducere ipsas, causa potandi tabernas intrare, per vicos et plateas sine decenti habitu discurrere et sine societate honesta domos alienas ingredi cuctis clericis inhibemus [...]» (Duffour 1907: 82-83). Vegeu, finalment, els estaments sinodals de l'arquebisbe de París Odon o Eudes de Sully -Odonis de Soliaco-, al tombant del segle XIII (Harlay 1674: 13); París, Bibliothèque nationale de France, MS Latin 14470, f. 182r.

8 Sanchis Francés (2019: II, doc. 1326.1). AHMV, Manual de Consells, sign. A-1, f. 283v (acord del 16 de setembre de 1326, ordenacions). Cf. Anyó García (2001: 399) i Furió \& Garcia-Oliver (2007: 165, núm. 172).

SCRIPTA, Revista internacional de literatura i cultura medieval i moderna, núm. 16 / desembre 2020 / pp. 300-319 ISSN: 2340-4841 · doi:10.7203/SCRIPTA.16.19232 
Raül Sanchis Francés. Connexions entre el ball i la prostitució en la tardor medieval: fembres pecadrius, reis arlots i çabies

poder fer front a aquesta pena, la dita fembra pecadriu romandria tancada deu dies als calabossos de la presó comuna. El 1334, regnant Alfons III el Benigne, el Consell es reafirma en la dita ordenació i en les penes, però, a més a més, especifica que les meretrius no podran ballar als ravals de la ciutat ni entrar-hi ballant: «Encara us fan saber que nengunes fembres públiques no gosen entrar ballan ne ballar en la ciutat ni en los ravals d'aquella, mas si ballar volran, pusquen ballar en lo loch que is és assignat per habitar e estar tan solament». ${ }^{9}$ D'ordenacions semblants se'n poden trobar arreu de les ciutats de la Corona d'Aragó. Per exemple, el 1389, a Girona s'establia que:

\begin{abstract}
Ítem, que quant alcuna fembre, per se gran malvestat e obre del diable, al bordell per se mala vida volrà guayar e contra la divinal volentat serà reebuda, licenciada per lo batle segons dit és en lo demunt dit capítol, no $\mathrm{n}$ sien fets ball per la ciutat ni encara en los bordells ni vehinats de aquells, com las christianes no 's degen alegrar de ço que lls diables se alegren. E si contra açò se fa, los hòmens e fembres qui ballaran paguen quescun .L. solidos o stien .c. dies en la presó, e los gulars [sic] qui hi sonaran perden les trompes, tabals e altres sturments qui là hi serviran, e pach quescun d'éls .c. solidos o stia .CC. dies en la presó de la dita ciutat (Rodrigo Lizondo \& Riera i Sans 2013: doc. 753).
\end{abstract}

Aquestes ordenacions degueren tindre una validesa perllongada en el temps ja que foren recollides fins i tot en una important obra compiladora de privilegis de la ciutat de València com l'Aureum opus..$^{10}$ L'objectiu d'extirpar de la ciutat «fembres pecadrius e àvols alcavots, putanes, jochs e jugadors, maldeints o altres» es feia més evident quan s’aproximava alguna visita reial, com per exemple la del rei Ferran, després de ser coronat a Saragossa, el 1412 (FIG. 4). ${ }^{11}$

Tant la disposició sinodal del segle XIII com les ordenacions del primer terç del segle XIV ens plantegen diverses qüestions que volem ressaltar. En primer lloc, des del mateix moment de la conquesta de València existí una prostitució més o menys regulada per l'administració local. Les dones públiques exercien les seues activitats sexuals i lúdiques al carrer, als hostals o a les tavernes i, des d'almenys el 1325, dins del marc d'un bordell habilitat als afores del recinte emmurallat de l'antiga ciutat andalusina que quedà integrat a la urbs amb l'ampliació de les murades sota el regnat de Pere el Cerimoniós, el 1356. Els balls formaven part el repertori d'estratègies que moltes meuques devien fer servir per atraure clients.

9 Sanchis Francés (2019: II, doc. 1334.1). AHMV, Manual de Consells, sign. A-3, f. 100rv (f. CIIIrv) (acord del 13 de juny de 1334, text de la crida). Cf. Furió \& Garcia-Oliver (2007: 261, núm. 280).

10 «Declaratio seu temperatio super facto mulierum peccatricium», privilegi CLIII, AUREUM OPUS (1515: F. LXXVI v). Aquest privilegi, concedit per Jaume II des de Tarassona, està datat el 14 de les calendes de setembre (19 d'agost) de 1325.

11 Sanchis Francés (2019: II, doc. 1414-1415.3). AHMV, Manual de Consells, sign. A-25, f. 127v. Cf. Narbona Vizcaíno (2012: doc. 63). El rei Ferran i la seua família no entraren a València fins a les acaballes de l'any 1414 i l'inici del 1415.

SCRIPTA, Revista internacional de literatura i cultura medieval i moderna, núm. 16 / desembre 2020 / pp. 300-319 ISSN: 2340-4841 · doi:10.7203/SCRIPTA.16.19232 
Raül Sanchis Francés. Connexions entre el ball i la prostitució en la tardor medieval: fembres pecadrius, reis arlots i çabies

\section{E1 rei Arlot}

El negoci de la prostitució era controlat per un personatge de difícil discerniment i estudi que rebia el nom de rei Arlot o rei dels arlots. ${ }^{12}$ Aquest càrrec, l'ofici del qual «era presidir a les dones pecadrius y portar-les y concertar-les ab los hòmens, y exigir tribut y penes de aquelles» (Ginart 1608: 310), fou actiu des dels temps de la conquesta de la ciutat ${ }^{13}$ fins a l'abolició dictada per Pere el Cerimoniós el 1338. ${ }^{14}$ Sembla que aquesta revocació fou momentània i no suposà l'extinció del càrrec, ja que el 30 de setembre de 1364, el rei Pere assignà a Mateu de Palerm, cavaller salvatge seu, l'ofici de rei Arlot a tota la seua senyoria (Cingolani 2016: 229-230).

Carboneres (1876: 19-20) el considera una institució local, però, segons Narbona Vizcaíno (2006), la figura d'aquest monarca és bastant més rica. Ha de ser entesa, en primer terme, com un rector de proxenetes « «amics especials» $-\mathrm{i}$ prostitutes que presenta correlats amb d'altres personatges semblants a diferents ciutats de la Corona i d'Europa. Però, a més a més, en opinió de Narbona, s'hauria de connectar amb una figura de caire popular que té un llarg recorregut festiu, almenys des del segle XIII, quan comença a aparèixer documentada: la dels reis efímers. ${ }^{15}$ El principal escull d'aquesta hipòtesi, com ja apuntava el mateix Narbona, és el caràcter temporal d'aquests reis efímers i el règim més o menys estable del càrrec dels reis arlots. La naturalesa exclusivament festiva dels primers i la condició institucional dels segons estableixen unes dissemblances que ens semblen difícils de salvar.

Cingolani (2016) acreix la documentació d'aquests reis arlots a tota la Corona d'Aragó i troba notícies de l'existència d'aquesta figura a Castella en un dels registres cancellerescos més interessants per al tema que ens ocupa, el referit a la reunió que Jaume II féu amb Ferran IV l’Emplaçat a Ariza, una població aragonesa situada ben a prop de la frontera amb Castella, per a preparar el setge d'Almeria. Les despeses de la trobada, ocorreguda el novembre de 1308, les havia d'assumir el rei que feia d'amfitrió. Jaume II pagà tant el cost dels joglars com el d'un abundant grup de soldaderes de les cases dels dos reis i de diversos nobles:

12 Sobre el rei Arlot de València, vegeu Narbona Vizcaíno (2006).

13 El Llibre del Repartiment de València documenta, tot just després de la conquesta, la cessió d'unes cases a un rei Arlot o rei dels arlots (de nom Garcia), a la zona ocupada pels homes de Tarragona, a l'est de la Jueria vella: «Garcia, rex Arlatorum: domos quas tenet in partita hominum Tarrachone et afrontant in domos de J. de Luna et de J. de Senpere. V idus decembris» (Bofarull Mascaró 1856: 308); «In vico hominum de Tarachona [...] Rex Irlotorum» (Bofarull Mascaró 1856: 620). Hom pot trobar aquests fragments i les corresponents traduccions del Llibre del Repartiment en una edició més moderna a càrrec de Ferrando Francés (1979 [1978]).

14 «De revocatione officii regis Arloti», privilegi viII, Aureum opus (1515: f. CIII-r). Aquest privilegi, concedit des de València, està datat en «pridie nonas marcii. Anno Domini .M.CCCXxxviI.», és a dir, el 6 de març de 1338.

15 Vegeu l'estudi que hem fet sobre els regnats efímers en relació amb les figures dels folls, els pàsseros i els galls a Sanchis Francés (2019: I, cap. 8.1.2), el qual forma part d'un treball de més llarg abast sobre l'alteritat coreofestiva valenciana que es publicarà aviat (Sanchis Francés [en premsa]).

SCRIPTA, Revista internacional de literatura i cultura medieval i moderna, núm. 16 / desembre 2020 / pp. 300-319 ISSN: 2340-4841 · doi:10.7203/SCRIPTA.16.19232 
Item, a Maria Pérez per XIIII soldaderes del rey de Castella, CCX torneses; item, a Maria Pérez per XI soldaderes de l'infant don Pedro, LXXXV torneses; item, a Maria Agnès per X soldaderes de l'infant don Johan, LXXX torneses; item, a VI soldaderes del comte de Portogal, L torneses; item, a Sanxa López, per VIII soldaderes de don Diego, LXXX torneses; item, a IIII soldaderes de l'infant don Phelipp, XL torneses; item, a IIII soldaderes d'en Johan Manuel, XL torneses; item, a dues soldaderes d'en Diego Garcia, XX torneses; item, a Theresa de Rada e a Sancha de Valenya, qui són del cuerpo de l'iffante don Johan, LX torneses; item, a II soldaderes de don Fferrando, ffill de don Diego, XX torneses; item, al rey Arlot de Castella, XX torneses; e axí són en summa DCCXV torneses, qui costaren a raó de V solidos III denarios per libra DCCCCII solidos VIII denarios barchinonenses (Cingolani 2016: 227).

Les soldaderes (prostitutes), les alcavotes (Maria Pérez, Maria Agnès, Sanxa López) i el rei Arlot de Castella, que sembla ser el coordinador de tot el grup, s'encarregaren de divertir les dues comitives. El sexe, els jocs, la música i la dansa complementaven el programa polític d'aquestes trobades, molt habituals durant l'edat mitjana.

En un altre context social, un dels fragments literaris que segurament il lustra millor la relació que hi havia entre el joc, la música, el ball i la vida a les tavernes -també als bordells-i els personatges del món rufianesc constituït per arlots, goliards i tafurs, equiparables moralment a golosos, ribalds i truans, ${ }^{16}$ és l'inici del capítol 76 del Romanç d'Evast e Blaquerna de Ramon Llull. En aquest episodi, Llull descriu com un persistent i ballaire canonge, malgrat el blasme dels seus conveïns, utilitza tàctiques de persuasió que intenten -i aconsegueixen, segons l'autor mallorquí- convertir a les bones costumes els clients habituals de moral distreta d'una taverna:

76. De PERSECUCIÓ

[1] Considerá lo canonge de persecució en lo gran carrech en lo qual era posat per rahó de son ofiçi, per ço que pugués husar de justicia. Esdevench-se un dia que ell passava devant una taverna on avia ajustats gran re de tafurs e de gulliarts e de arlots, los quals bevien en la taverna e cantaven e ballaven e sonaven struments. Lo canonge entrá en la taverna e comprá del vi e ballá ab los tafurs e dix estes cobles de Nostra Dona:

[2] -A vos, dona verge santa Maria [...]

[5] Con les hac dites, ell pregá que seguesen e beguesen e contassen algunes paraules agradables. Dementre que lo canonge era enfre aquelles gents, los homens qui passaven per la carrera l'escarnien e 11 reprenien per ço cor era en companya de tant vils homens. E lo canonge, aytant com pudia, fahia con fos amat per aquells ab qui estava e tuyt avien bon saber de sa companya e fahien cap d'el e scoltaven ses paraules, les quals dehia de Jesucrist e dels apostols e del menyspreament d'aquest mon. En tant dolçes paraules los tenia e tantes vegades la setmana se metia en companyia d'aytals homens, que molts ne convertia a bones custumes e a bons nudriments, sens que no 's n'estava per lo blasme de les gents (Llull 2009: 333-334).

16 Vegeu la nota crítica a peu de pàgina de Soler i Santanach en què s'anota la versió d'aquest fragment a partir d'un testimoni francés de finals del segle xiII: «ribauz et de gouliarz, tafurers: e golosos; e truans: y altres homens ribalts». 
Raül Sanchis Francés. Connexions entre el ball i la prostitució en la tardor medieval: fembres pecadrius, reis arlots i çabies

\section{Les çabies sarraïnes i l'impost de la tarquena}

En la societat medieval hi havia diferents tipus de marginació: pel gènere, per la religió, per la condició socioeconòmica, per l'origen, etc. La discriminació es palesava de moltes maneres. Dues de les més notòries, eren la forma de vestir, mitjançant ordenacions que determinaven les robes que podien dur o havien de dur obligatòriament els diferents col lectius, i el lloc on havien de viure aquestes comunitats: els musulmans a la moreria, els jueus als calls $\mathrm{i}$ les prostitutes al bordell (FIG. 5).

Però, com hem dit abans, hi havia moltes classes de meuques. Per un costat, estaven les dones públiques, que s'havien de registrar com a tals i pagar uns determinats impostos que els permetien exercir legalment la professió. D’altra banda, les prostitutes clandestines actuaven al marge de la llei i eren perseguides, així com els proxenetes que les explotaven i els hostalers que les albergaven. Tanmateix, encara que és difícil fer una valoració quantitativa d'aquest fenomen il legal, la prostitució clandestina era força present als carrers $i$ als ravals de la ciutat.

Una menció especial mereixen les çabies sarraïnes o mores, ja que era un col lectiu triplement marginat en la societat medieval: per la condició de dones, per ser musulmanes i per practicar la prostitució (Rangel López 2008). Segons Corriente (2003: 429, 439), la veu catalana sabia, ortografiada també com a çabia, «parece significar [i efectivament significa] 'manceba, concubina', como él mismo [Coromines] explica». El mateix autor recull que l'ètim prové de l'andalusí șabíyya i de l'àrab clàssic șabiyyah, una veu documentada freqüentment en català. També s'hi registra en alguna ocasió el masculí diminutiu sobai, que significa 'esclau, adolescent'. Com observa Barceló (2011: 113) en un monogràfic seu sobre els contactes i els contrastos entre l'àrab i el català, sabia presenta l'accentuació d'arabismes com alqueria, aldeha o el topònim Canesia. Aquesta autora aporta diversos documents del segle XV que reforcen l'accepció de «çabia mora» com a 'prostituta, bagassa'. També recull, d'anteriors publicacions seues, una etimologia relacionada amb l'arrel ș $b w$ que «implica la idea de joventut». Per tant, les çabies o sabies devien ser fembres públiques joves i mores.

Ara bé, no totes les fembres públiques mores es movien en entorns de baixa casta. Algunes podien arribar a tindre un cert prestigi $\mathrm{i}$ un bagatge cultural i professional suficient per considerar-les dignes d'entrar al servei de reis i prínceps. És il lustratiu el cas d'una valenciana de nom Fotoix, «fembra pública» i «apta balladora», procedent de Benaguasil. El 1406 el rei Martí demana al batlle de Xàtiva, ciutat on es troba la dita dona, que envie a València aquesta ballarina perquè exercesca «en son offici» i s'incorpore al nodrit grup de «mores alfulells» que ja té el monarca al seu servei (Girona Llagostera 1913-1914: 595, doc. 539). No és casualitat que Fotoix estiguera a Xàtiva, una ciutat que, de fet, albergà una de les escoles joglaresques més importants del Xarq Alandalús. Encara més, durant la primera època de la conquesta cristiana (segles XIII-XV), la fama dels joglars xativins fou notable. Aquests músics, ballaires, actors, prestidigitadors i acròbates foren contractats per actuar en celebracions règies de primera magnitud com ara coronacions i casaments (FIG. 6). Diferents 
Raül Sanchis Francés. Connexions entre el ball i la prostitució en la tardor medieval: fembres pecadrius, reis arlots i çabies

grups i nissagues com la dels Alfuley tingueren una activitat remarcable i duradora en el temps (Massip \& Sanchis Francés 2016: 505-511; 2017a; 2017b: 38-43). ${ }^{17}$

Amb major o menor càrrega eròtica, el repertori de representacions i balls que executaven aquesta mena de joglaresses, no sempre sota la condició de prostitutes, devia ser divers i semblant al de la tradició islàmica, exportada a Alandalús, com es pot deduir a partir de la documentació conservada i de l'abundant iconografia: contorsionismes, jocs amb cavallets (kurraj), malabarismes amb espases, punyals, pilotes i altres objectes, cants, interpretacions musicals, recitacions poètiques, imitacions, escenificacions amb màscares, teatre d'ombres, narracions d'històries, balls adornats amb cascavells, vels, cròtals i tauletes, a més de les representacions de caire eròtic (FIG. 7) ${ }^{18}$ Recordem, en aquest sentit, un document de 1338 protagonitzat per Pere Çahat, en el qual apareix com a «magistrum ludi amoris», és a dir, una mena de director d'una companyia de joglars moros especialitzada en representacions de caràcter amorós. ${ }^{19}$

Les çabies musulmanes o els seus amics especials (els alcavots) havien de pagar un gravamen fix, documentat majoritàriament com a tarquena o tarchana, si volien inscriure's als registres oficials $\mathrm{i}$ regular-ne la situació professional. Per exemple, el 1268 i el 1269, diverses prostitutes musulmanes ja figuren com a contribuents d'aquest impost a Sumacàrcer i a Pego (Burns 1981: 460). A Cocentaina, també en el segle xiII, gràcies a les referències de la subhasta o adjudicació de regalies, sabem que les rendes pels drets de tarchana de la ciutat i del seu terme sumaven dos-cents sous (Torró 2009: 127, 137, 233). En alguna ocasió, fins i tot el rei va voler explotar directament aquest dret, sense fer-ne efectiu l'arrendament (Ponsoda Sanmartín 1992: II, 712). Les fembres públiques que volien inscriure's com a tals als municipis de la vall de Segó (integrada a l'actual comarca del Camp de Morvedre) havien de pagar un sou cadascuna. Hom pot trobar registres de finals del segle XIV d'aquest impost abonat per jóvens procedents d'Aiòder, Almedíxer, Almonesir, Bétera, Nàquera, Riba-roja, la Vall d’Uixó i Xàtiva (Silvestre Romero 2004: 30, 61, 119, 123, 125). Segons la documentació de les rendes senyorials del lloc d'Ondara a principis del segle xv, una «mora çabia» hagué de pagar 2 sous i 6 diners per haver exercit la prostitució tres vegades, és a dir, deu diners per cada vegada que s'havia gitat amb algun home (Hinojosa Montalvo 2008-2010: 44). Del total dels ingressos d'una batllia com la de Sogorb, al segle xv, el dret de tarquena de la moreria representava

17 Sobre l'origen i el significat del terme fuley o alfuley (topònim Alfuley, atribut ètnic de mulato o procedència del terme àrab fulān, del qual deriven fulano en castellà i fulà en català), documentat amb múltiples variants, vegeu Sanchis Francés (2019: I, 279). Notem també l'estreta relació entre fuley i fulana, és a dir, prostituta.

18 Vegeu, per exemple, l'extens repertori que ofereix la tradició teatral, poètica, musical i corèutica islàmica i andalusina a: Pérès (1990 [1937]); Shiloah (1962); Moreh (1992); Cortés García (2007); Corriente (2014), i Massip \& Sanchis Francés (2016; 2017a; 2017b). Vegeu també l'estudi introductori als Archivos moriscos de Barceló \& Labarta (2016) i les apreciacions que sobre aquests arxius i d'altres informacions dels balls moriscos aportem a Sanchis Francés (2019: I, cap. 5.3).

19 Pere el Cerimoniós, mitjançant un salconduit emés a València, posa sota la seua protecció els membres de la companyia del mestre del joc d'amor Pere Çahat i els dona guiatge perquè puguen actuar lliurement als seus territoris (Massip 2011: 10-11). 
Raül Sanchis Francés. Connexions entre el ball i la prostitució en la tardor medieval: fembres pecadrius, reis arlots i çabies

no més d'un u per cent (López Rodríguez 2005: 105). Pels voltants de 1470, un dels ingressos de la Corona era l'arrendament de «la batlia de les çabies» de la moreria de València (Barceló 2011: 113). Aquests tributs deixaren de cobrar-se, lògicament, amb l'expulsió dels moriscos.

Segons la documentació que recull Meyerson (1991: 155) a la València de finals del segle xv, l'encarregat de recaptar aquest dret reial era l'alfondeguer, amb la col laboració del bastó, una mena d'oficial que vigilava la moreria, dirigia la taverna reial $\mathrm{i}$ el bordell i cobrava la tarquena a les prostitutes sarraïnes o als seus proxenetes. A l'alfòndec es trobaven els comerciants locals i forans. Sovint, quan acabaven de fer negocis, anaven a la taverna i al prostíbul a divertir-se. Segurament, una de les atraccions prèvies a la de mantenir relacions sexuals amb les dones públiques era veure-les actuar i ballar.

Moltes prostitutes mantenien relacions amb clients de qualsevol religió, malgrat el risc que això podia comportar. En principi, els cristians intimaven sexualment amb dones de totes les condicions religioses, però en cas contrari, quan els sarraïns -o els jueus- es gitaven amb una cristiana eren multats i perseguits amb penes que podien comportar la mort. ${ }^{20}$

Però també podem documentar un significat complementari per a tarquena o tarchana. Precisament, Ferrer i Mallol (1988: 61) acredita el terme tarchana en un document de 1303 que registra un manament de Jaume II mitjançant el qual se suprimeix aquest impost a la vila d'Elx. Ferrer interpreta que es tracta d'un lloc físic de la moreria - un bordell o una casa de joc- que havia de ser destruit, però també apunta la possibilitat que la tarchana fora un impost que es pagara per les festes de noces musulmanes. Es basa en la informació recollida per Reinhart Dozy sobre l'ètim țarqūn, un terme que es pot relacionar amb «saltare» (Vocabulista in arabico). A partir de diversos textos, un dels quals narra una anècdota protagonitzada per un xativí, Dozy (1927: 39) dedueix que: «Le tarcoun était, par conséquent, le receveur de l'impôt établi sur les festins de noces, et comme la danse, aussi bien que la musique, faisait partie des réjouissances qui accompagnaient le mariage, on compred porquoi le Voc. [Vocabulista in arabico] a mis le tarcoun en rapport avec le verbe «saltare»». Per una altra banda, podria reforçar aquesta idea de l'acompanyament musical de les noces una de les accepcions del mot àrab țarq 'tocar, fer sonar' (Corriente \& Ferrando 2005: 708). ${ }^{21}$

20 Per exemple, durant el regnat de Martí I l'Humà apareixen explícitament anomenats a la documentació cancelleresca tres «moros qui ballen»: Asant, Marian i Essuley (àlies Macit), el fill del qual és multat per haver-se gitat amb una cristiana el 1404 en un bordell de Barcelona (Sanchis Francés 2019: I, 281-282). Vegeu les abundoses notícies que proporciona Ferrer i Mallol (1987: esp. 30-37) sobre aquests aspectes. Vegeu també el cas, entre d'altres, de Maria de Biscaia, una prostituta que exercia al bordell d'Elx el 1456. Aquesta meretriu «advertí que el seu client era moro quan li veié el membre». Alí Laye, el client, que devia entendre's perfectament amb la dita Maria de Biscaia en la seua llengua, fou empresonat per haver jagut carnalment amb una cristiana, però fou posat en llibertat per la intervenció del comte de Cocentaina, senyor d'Asp, del qual era vassall (Garrido i Valls 2016: 128).

21 Hinojosa Montalvo (2008-2010: 43) també documenta a Ondara el dret de cuçea, un impost arrendable que gravava una tercera part del salari percebut pels joglars que amenitzaven les noces dels mudèjars. En altres localitats aquesta càrrega es coneixia sota el nom de dret del juglar. 
Raül Sanchis Francés. Connexions entre el ball i la prostitució en la tardor medieval: fembres pecadrius, reis arlots i çabies

En consonància amb aquesta interpretació podem enquadrar perfectament el terme «tarquene» que apareix en un document cancelleresc datat el 1389. El rei Joan I concedeix a Massot o Maçot Alfuley, un mim i histrió sarraí de Xàtiva, els drets de la tarquena, que ara estan relacionats amb les activitats musicals pròpies dels casaments del col lectiu sarraí (Trenchs Òdena \& Baiges i Jardí 2000-2002: doc. 183).

Anys a venir, reforça encara més aquest significat la confluència de diversos documents sobre el convers granadí Ayaya Fisteli, rebatejat com a Fernando Morales. És significativa, en primer terme, la carta reial remesa a les autoritats de Granada el 13 de febrer de 1492, tot just després de la conquesta de la ciutat, mitjançant la qual els monarques Ferran d'Aragó i Isabel de Castella atorguen a favor de Fisteli una mercé que li adjudica, seguint l'antic costum del regne nassarita, l'ofici d'alcaid de les joglaresses i els joglars de Granada:

\footnotetext{
Merçed de un Alcaide de Granada.

Nos don Fernando e donna Ysabel, etç. Por fazer bien e merçed a vos Ayaya Fisteli, es Nuestra Merced e Voluntad que agora e de aquí adelante, para en toda vuestra vida, seades Alcaide de las juglaras e juglares de la çibdat de Granada.

E llevades los derechos e salario al dicho ofiçio anexos e pertenencias según que acostumbraron llevar los alcaides que fueron de los Reyes Moros pasados [...]; apud Quesada Gómez \& Fernández Manzano (1983).
}

Gràcies a la documentació conservada d'un pleit que s'inicià el 1517, se sap que Fisteli, en relació amb aquest ofici, s'encarregava de cobrar l'impost del «tarcón», un cànon que havien de pagar els joglars moriscos per poder participar en zambras i casaments. L'impost servia, entre d'altres destinacions, per pagar els rescats dels captius que eren esclavitzats a terres de Berberia. Finalment, amb la mort de Fisteli el 4 de gener de 1519, els joglars granadins quedaren alliberats de pagar el tarcón (Quesada Gómez \& Fernández Manzano 1983; Cortés López 1989: 231).

\section{Conclusions}

En aquest estudi analitzem les relacions existents entre el ball i la pràctica de la prostitució a la tardor medieval, sobretot en l'entorn geogràfic valencià. En primer lloc, comprovem que hi havia meretrius de totes les condicions socials i orientacions religioses i que algunes d'elles utilitzaven els balls sensuals per atraure més clients. Per l'ús que feien del seu cos, tant des del punt de vista sexual com corèutic, les fembres pecadrius eren blasmades sobretot pels predicadors i els teòlegs. Malgrat tot, sembla imposar-se una moral basada en el mal menor agustinià que induirà els governants a tolerar la prostitució sota uns condicionants. Així, durant la baixa edat mitjana, les administracions locals i reials emeten regularment diverses disposicions que la reglamenten. A partir dels segles XIII i XIV, s'habiliten bordells sota la custòdia de les autoritats locals i generals amb els gravàmens pertinents. 
Raül Sanchis Francés. Connexions entre el ball i la prostitució en la tardor medieval: fembres pecadrius, reis arlots i çabies

A València, la Pobla de les fembres pecadrius es convertirà, principalment durant els segles XV i XVI, en un dels prostíbuls més grans i reconeguts de tot Europa. Durant algun temps (almenys fins a la segona meitat del segle XIV), aquests locals són controlats per figures com la del rei Arlot, una mena de càrrec oficial que tenia per objecte presidir les fembres pecadrius, concertar les relacions sexuals amb els clients, exigir els tributs que gravaven l'exercici de l'ofici i imposar penes i multes a qui contravenia les normes establertes. A més de practicar el sexe als bordells i a les tavernes, les prostitutes hi ballaven i realitzaven espectacles de tot tipus, especialment de caire eròtic. Aquestes activitats, però, eren perseguides als ravals i fora dels recintes permesos. Atenció especial mereixen en el nostre estudi les sabies o çabies mores, un col lectiu triplement marginat, per la condició de dones, per ser musulmanes i per practicar la prostitució. Ara bé, no totes les fembres públiques mores es movien en entorns de baixa casta, sinó que algunes podien arribar a prestar els seus serveis a alts dignataris, nobles i monarques. Aquestes çabies pagaven determinats impostos per a poder exercir el seu ofici: la tarquena o tarchana. El conjunt d'aquestes taxes eren subhastades i arrendades. Fins i tot el rei podia reservar-se l'explotació directa d'aquest dret. Aquest tribut, documentat com a tarcón a l'antic regne nassarita de Granada, sembla carregar també les activitats musicals dels joglars a les noces i les sambres del col lectiu sarraí i morisc. 
Raül Sanchis Francés. Connexions entre el ball i la prostitució en la tardor medieval: fembres pecadrius, reis arlots i çabies

\section{Bibliografia}

Anyó García, V. (ed.) (2001) Elprimer manual de consells de la ciutat de València (1306-1326), València, Ajuntament de València.

Aureum opus (1515) Aureum opus regalium privilegiorum civitatis et regni Valentie cum historia cristianissimi Regis Jacobi ipsius primi conquistatoris, València, Dídac [Didaci] de Gumiel.

Barceló, C. (2011) Àrab i català: contactes i contrastos, València/Barcelona, Institut Interuniversitari de Filologia Valenciana/Publicacions de l'Abadia de Montserrat.

Barceló, C. \& Labarta, A. (ed.) (2016) Cancionero morisco. Poesía árabe de los siglos XV y XVI, València, Ángeles Carrillo Baeza.

Benito Julià, R. (2018) La prostitució a la Barcelona Baixmedieval (segles XIV-XV), Tesi doctoral dirigida per Rosa Lluch Bramon, Universitat de Barcelona, Barcelona.

Bofarull Mascaró, P. de (ed.) (1856) Colección de documentos inéditos del Archivo General de la Corona de Aragón. Repartimientos de los Reinos de Mallorca, Valencia y Cerdeña, vol. XI, Barcelona, En la imprenta del archivo.

Boix, V. (1855) Apuntes históricos sobre los fueros del antiguo Reino de Valencia, València, Imprenta de D. Mariano de Cabrerizo.

Burns, R. I. (1981) «Los mudéjares de Valencia: temas y metodología», Actas del I Simposio internacional de mudejarismo (15-17 Septiembre 1975, Teruel), Teruel, Instituto de Estudios Turolenses/Consejo Superior de Investigaciones Científicas/Diputación Provincial de Teruel, pp. 453-497.

Cabezuelo Pliego, J. V. (2019) «Placer, pecado, delito. Sexualidad y violencia sexual en la frontera meridional valenciana a fines de la Edad Media. Algunos ejemplos», Mirabilia/MedTrans, 10 (2), pp. 233-263. DOI/HDL: http://hdl.handle.net/10045/101642

Carboneres, M. (1876) Picaronas y alcabuetes o la Mancebia en Valencia. Apuntes para la bistoria de la prostitución, València, Librería de Pascual Aguilar.

Cingolani, S. M. (2016) «Entretenimientos, fiestas, juegos y placeres a la corte de los reyes de Aragón en el siglo XIV», En la España Medieval, 39, pp. 225-248. DOI/HDL: https://doi.org/10.5209/ rev_ELEM.2016.v39.52339

Corriente, F. (2003) Diccionario de arabismos y voces afines en iberorromance, 2a ed., Madrid, Gredos.

- (2014) «Del 'teatro de sombras' islámico a los títeres, pasando por los 'retablos de maravillas'», Revista de Filología Española, 94 (1), pp. 39-56. DOI/HDL: https://doi.org/10.3989/rfe.2014.02

Corriente, F. \& Ferrando, I. (2005) Diccionario avanzado árabe, vol. I (árabe-español), 2a ed., Barcelona, Herder.

Cortés García, M. (2007) «Poesía, música y danza en la Granada musulmana y morisca», Cuadernos de Arte de la Universidad de Granada, 38, pp. 9-41. 
Raül Sanchis Francés. Connexions entre el ball i la prostitució en la tardor medieval: fembres pecadrius, reis arlots i çabies

Cortés López, J. L. (1989) La esclavitud negra en la España peninsular del siglo XVI, Salamanca, Universidad de Salamanca.

Dozy, R. (1927) Supplément aux dictionnaires arabes, vol. II, 2a ed., Leide, Librairie et imprimerie Cidevant E.-J. Brill.

Duffour, J. (ed.) (1907) Livre rouge du Chapitre métropolitain de Sainte-Marie d'Auch, París, Honoré Champion.

Ferrando Francés, A. (ed.) (1979 [1978]) Llibre del Repartiment de València, Paterna, Vicent Garcia.

Ferrer i Mallol, M. T. (1987) Els sarraïns de la Corona catalano-aragonesa en el segle XIV. Segregació $i$ discriminació, Barcelona, Consell Superior d'Investigacions Científiques.

(1988) Les aljames sarraïnes de la governació d’Oriola en el segle XIV, Barcelona, Consejo Superior de Investigaciones Científicas.

Furió, A. \& Garcia-Oliver, F. (ed.) (2007) Llibre d'establiments i ordenacions de la ciutat de València .I. (1296-1345), València, Universitat de València.

Garrido i Valls, J.-D. (2016) «L'àrab i el català en contacte al migjorn valencià: el Baix Vinalopó en el segle XV», La Rella, 29, pp. 115-140.

Ginart, O. B. (1608) Repertori general y breu sumari per orde alphabètich de totes les matèries dels Furs de València, fins a les Corts de l'any 1604, inclusive, y dels privilegis de dita Ciutaty Regne, València, en casa de Pere Patricio Mey.

Girona Llagostera, D. (1913-1914) «Itinerari del rey en Martí (1403-1410)», Anuari de l'Institut d'Estudis Catalans, 5, pp. 515-654.

González Martí, M. (1944) Cerámica del Levante español. Siglos medievales, Vol. I (Loza), Barcelona, Labor.

Grau Monserrat, M. (1978) «El Bordell medieval de Morella», Boletin de Amigos de Morella y su Comarca, IV, pp. 27-36.

Graullera Sanz, V. (1990) «Los hostaleros del burdel de Valencia», Revista d’Història Medieval, 1, pp. 201-213.

(2006) «El fin del burdel de Valencia (s. XIII al XVIII)», dins Córdoba de la Llave, R. (ed.) Mujer, marginación y violencia entre la Edad Media y los tiempos modernos, Córdoba, Universidad de Córdoba, pp. 357-376.

Guillot Aliaga, D. (2015) «Mujer y marginación: prostitutas, alcahuetas y concubinas en la ciudad de Valencia (XIV-XVII)», dins Iglesias Rodríguez, J. J. / Pérez García, R. M. / Fernández Chaves, M. F. (eds.) Comercio y cultura en la Edad Moderna. Comunicaciones de la XIII Reunión Científica de la Fundación Española de Historia Moderna, Sevilla, Universidad de Sevilla, pp. 2025-2037. DOI/ HDL: http://dx.doi.org/10.20350/digitalCSIC/12231 
Raül Sanchis Francés. Connexions entre el ball i la prostitució en la tardor medieval: fembres pecadrius, reis arlots i çabies

Harlay, F. de (ed.) (1674) Synodicon Ecclesiae Parisiensis, Paris, Apud Franciscum Muguet Regis.

Hillgarth, J. N. \& Silano, G. (1984) «A compilation of the diocesan synods of Barcelona (1354): Critical edition and analysis», Mediaeval Studies, 46 (1), pp. 78-157. DOI/HDL: 10.1484/J. MS.2.306312

Hinojosa Montalvo, J. (2008-2010) «Ondara, señorío del duque de Gandía, a principios del siglo XV», Sharq Al-Andalus, 19, pp. 35-68. DOI/HDL: 10.14198/ShAnd.2008-2010.19.02

Llull, R. (2009) Romanç d'Evast e Blaquerna, Soler, Albert \& Santanach, Joan (ed.), Palma, Patronat Ramon Llull.

López Rodríguez, C. (2005) Nobleza y poder político en el Reino de Valencia (1416-1446), València, Universitat de València.

Massip, F. (2011) «Huellas de Petrarca tras los espectáculos de entrada real en la confederación catalano-aragonesa (1397-1414)», Annali di storia moderna e contemporanea, 17, pp. 7-32. DOI/ HDL: $10.1400 / 209193$

- . (2012) «Joglaria i activitat dramàtica», Medievalia, 15, pp. 317-348. DOI/HDL: https://doi. org $/ 10.5565 / \mathrm{rev} /$ medievalia.20

Massip, F. \& Sanchis Francés, R. (2016) «Traces musulmanes dans le théâtre médiéval européen», Revue des Langues Romanes, 120 (2), pp. 491-516. DOI/HDL: 10.4000/rlr.418

- (2017a) «Addenda et corrigenda: Traces musulmanes dans le théâtre médiéval européen», Revue des Langues Romanes, 121 (1), pp. 327-330.

— - (2017b) «Traces islàmiques en el teatre medieval europeu. La joglaria sarraïna a la Corona d’Aragó», dins Sanchis Francés, R. \& Massip, F. (eds.) La dansa dels altres. Identitat $i$ alteritat en la festa popular, Catarroja, Barcelona, Afers, pp. 25-46.

Meyerson, M. D. (1991) The Muslims of Valencia in the Age of Fernando and Isabel: Between Coexistence and Crusade, Berkeley, Los Angeles \& Oxford, University of California Press.

Moreh, S. (1992) Live Theatre and Dramatic Literature in the Medieval Arabic World, Edimburg, University Press.

Narbona Vizcaíno, R. (2006) «El Rey Arlot de Valencia. Poder público, desorden y rufianismo en el siglo XIV», dins Córdoba de la Llave, R. (ed.) Mujer, marginación y violencia entre la Edad Media y los tiempos modernos, Còrdova, Universidad de Córdoba, pp. 201-240.

- (2012) «Las leyes de pobres en la metrópolis. Mendigos, miserables, trabajadores en Valencia, 1306-1462», Clio \& Crimen, 9, pp. 165-284.

Pérès (1990 [1937]) Esplendor de al-Andalus: La poesía andaluza en árabe clásico en el siglo XI. Sus aspectos generales, sus principales temas y su valor documental, 2a ed., Madrid, Hiperión.

Pérez de Heredia y Valle, I. (ed.) (1994) Sinodos medievales de Valencia. Edición bilingüe, Roma, Instituto Español de Historia Eclesiástica. 
Raül Sanchis Francés. Connexions entre el ball i la prostitució en la tardor medieval: fembres pecadrius, reis arlots i çabies

Pérez García, P. (1991) «Un aspecto de la delincuencia común en la Valencia pre-agermanada: la 'prostitución clandestina' (1479-1518)», Revista de Historia Moderna. Anales de la Universidad de Alicante, 10, pp. 11-41. DOI/HDL: http://dx.doi.org/10.14198/RHM1991.10.01.

Peris, M. C. (1990) «La prostitución valenciana en la segunda mitad del siglo XIV», Revista d'Història Medieval, 1, pp. 179-199. DOI/HDL: http://hdl.handle.net/10550/29602.

Ponsoda Sanmartín, J. J. (1992) La llengua catalana a Cocentaina al segle XIII segons el Llibre de la Cort de Justícia, Tesi doctoral dirigida per Jordi Colomina i Castanyer, Universitat d'Alacant, Alacant.

Quesada Gómez, M. D. \& Fernández Manzano, R. (1983) «Documento relativo a la historia institucional de la música en el reino nazarí de Granada», Gazeta de Antropología, 2 (artículo 08).

Rangel López, N. (2008) «Moras, jóvenes y prostitutas: acerca de la prostitución valenciana a finales de la Edad Media», Miscelánea Medieval Murciana, 32, pp. 119-130. DOI/HDL: http://dx.doi. org $/ 10.6018 / \mathrm{j} 49321$.

Rodrigo Lizondo, M. \& Riera i Sans, J. (ed.) (2013) Col tecció documental de la Cancelleria de la Corona d'Aragó: Textos en llengua catalana (1291-1420), València, Universitat de València.

Sanchis Francés, R. (2019) La dansa metaforica en la festa valenciana, Tesi doctoral dirigida per Francesc Massip, Universitat Rovira i Virgili, Tarragona.

- ([en premsa]) Els altres en l'imaginari coreofestiu valencià. De l'edat mitjana a les pervivències actuals, Barcelona, Publicacions de l'Abadia de Montserrat.

Sanchis Sivera, J. (1935) Vida intima de los valencianos en la época foral: publicados en los Anales del centro de cultura valenciana números 14 al 21, València, Imprenta Hijo de F. Vives Mora.

Shiloah, A. (1962) «Réflexions sur la danse artistique musulmane au moyen âge», Cahiers de Civilisation Médiévale, 20, pp. 463-474.

Silvestre Romero, A. (ed.) (2004) Els llibres de comptes de la batllia de Morvedre a la fi del segle XIV, València, Universitat de València.

Toldrà, A. (2011) Asmodeu. Dona, dimoni i sexe a l'edat mitjana, València, Universitat de València.

Torró, J. (ed.) (2009) Llibre de la Cort del Justícia de Cocentaina (1269, 1275-1278, 1288-1290), València, Universitat de València.

Trenchs Òdena, J. \& Baiges i Jardí, I. (2000-2002) «Documents sobre música, musics i instruments musicals a la casa reial catalano-aragonesa (segles XIV-XV): el regnat de Joan I», Estudis castellonencs, 9, pp. 137-317.

Viciano, P. (2005) «El bordell dels prohoms. El control municipal de la prostitució al Castelló del segle XV», Anuario de estudios medievales, 35 (1), pp. 327-358. DOI/HDL: 10.3989/aem.2005.v35. i1.142.

Vidal Gavidia, M. A. (2001) La Casa de Arrepentidas de Valencia. Origen y trayectoria de una institución para mujeres, València, Consell Valencià de Cultura. 
Raül Sanchis Francés. Connexions entre el ball i la prostitució en la tardor medieval: fembres pecadrius, reis arlots i çabies

\section{Figures}
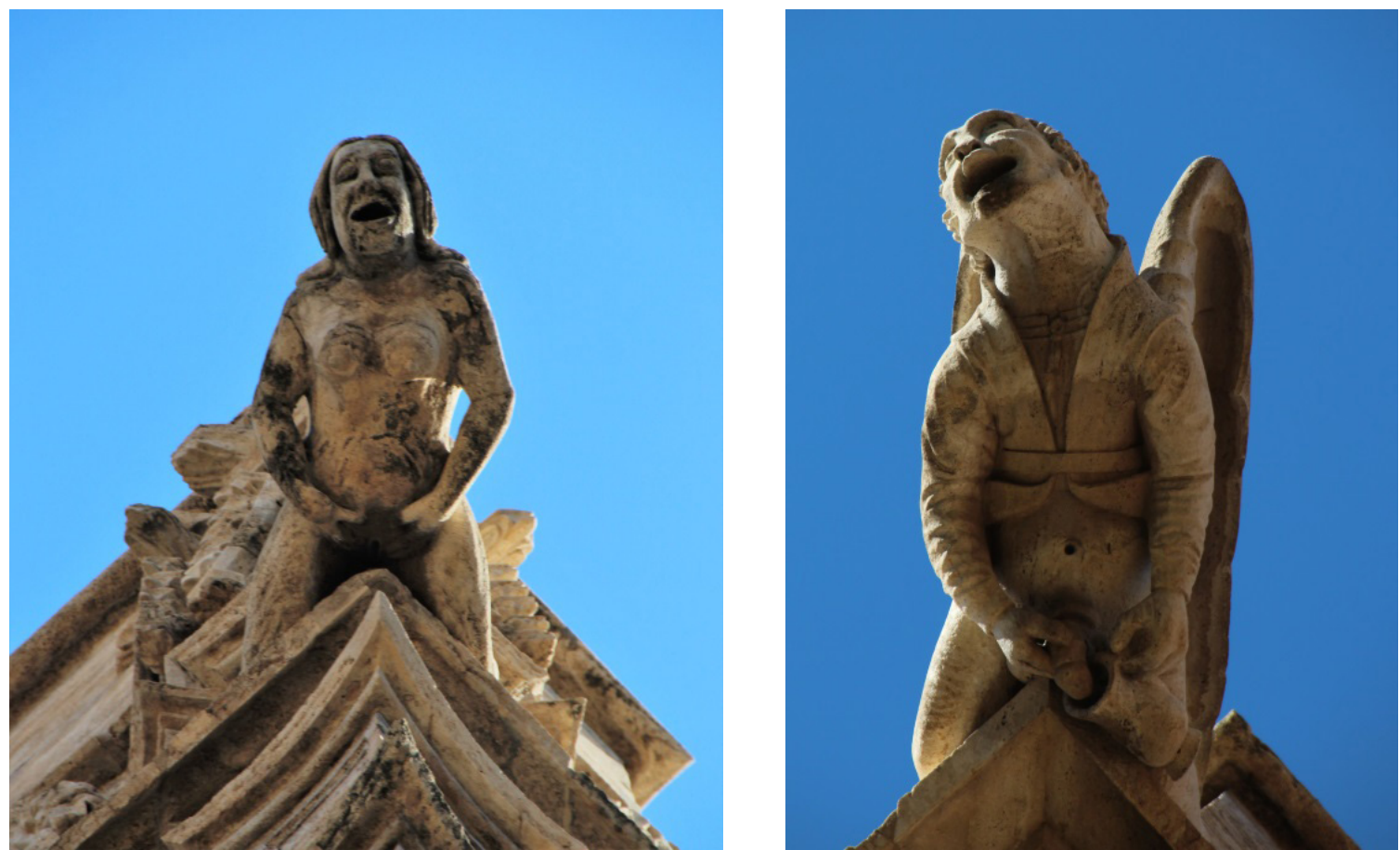

FIG. 1: Gàrgoles grotesques i obscenes que representen els vicis, la lascívia i la luxúria o, segons d'altres interpretacions, satiritzen la societat valenciana del segle xv, Llotja de Mercaders de València, iniciada el 1482 pel mestre d'obres Pere Comte (Girona, s. Xv - València, 1506). Una dona completament nua s'obri ostensiblement els llavis genitals (esquerra). Una figura alada es toca el penis i orina a una gerra (dreta) [fotografies: Raül Sanchis].

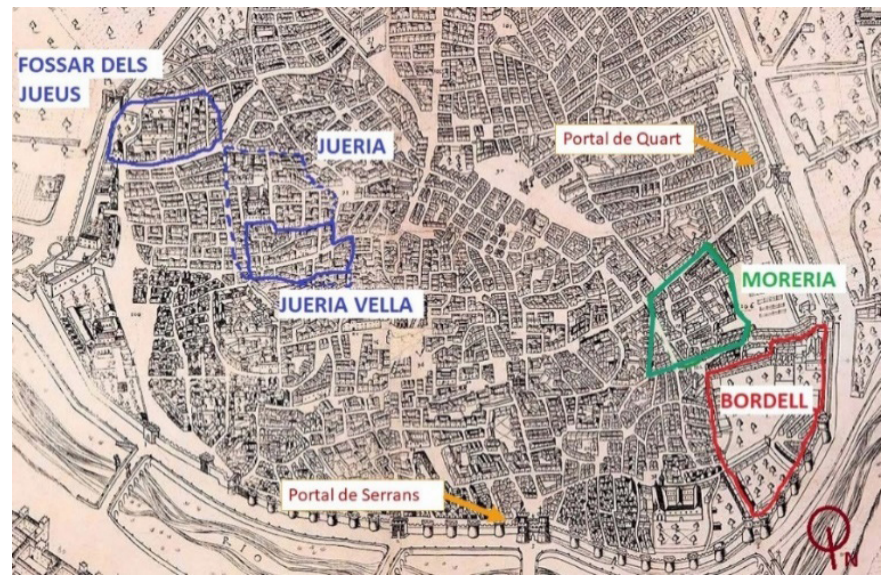

Fig. 2: Detall del plànol cartogràfic d'Antonio Mancelli (Museu Històric Municipal de València, Nobilis ac Regia Civitas Valentie in Hispania, 1608) amb la localització aproximada del fossar dels jueus, de la jueria vella cap al 1240 (en blau i les posteriors ampliacions fins al pogrom de 1391 (línia discontínua), la moreria (en verd) i el bordell (en roig) [Infografia d'elaboració pròpia].

SCRIPTA, Revista internacional de literatura i cultura medieval i moderna, núm. 16 / desembre 2020 / pp. 300-319 ISSN: 2340-4841 · doi:10.7203/SCRIPTA.16.19232 
Raül Sanchis Francés. Connexions entre el ball i la prostitució en la tardor medieval: fembres pecadrius, reis arlots i çabies

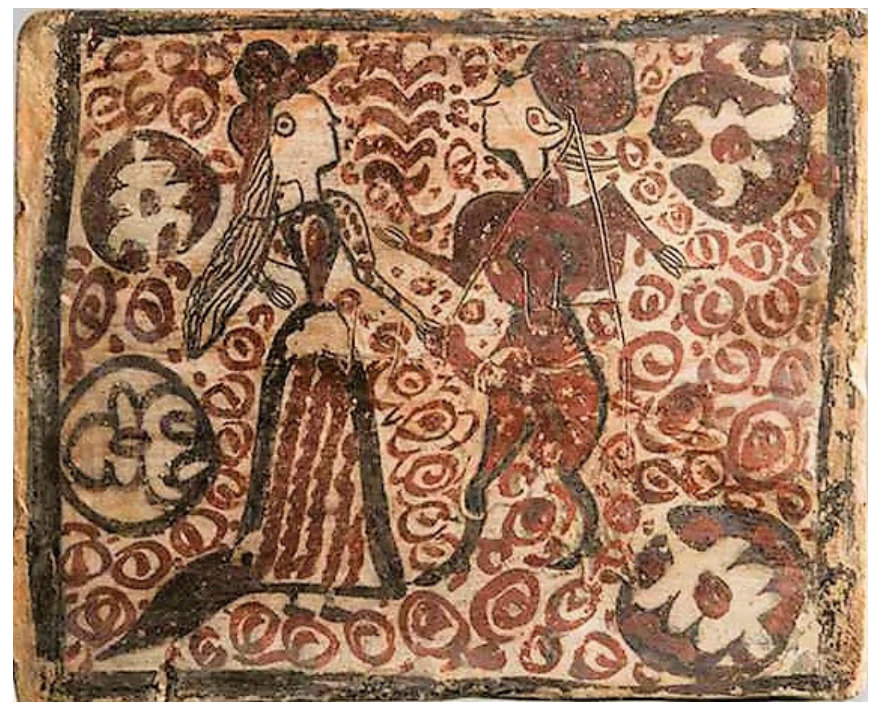

Fig. 3: Socarrat decorat amb òxid de ferro i manganés, Paterna, segle xv. S'hi representa una escena de tema eròtic. La dama de l'esquerra, amb tota probabilitat una prostituta, acaricia el penis de la figura masculina de la dreta [Barcelona, Museu del Disseny, núm. inv. MCB 19489; fotografia: Guillem Fernández-Huerta].

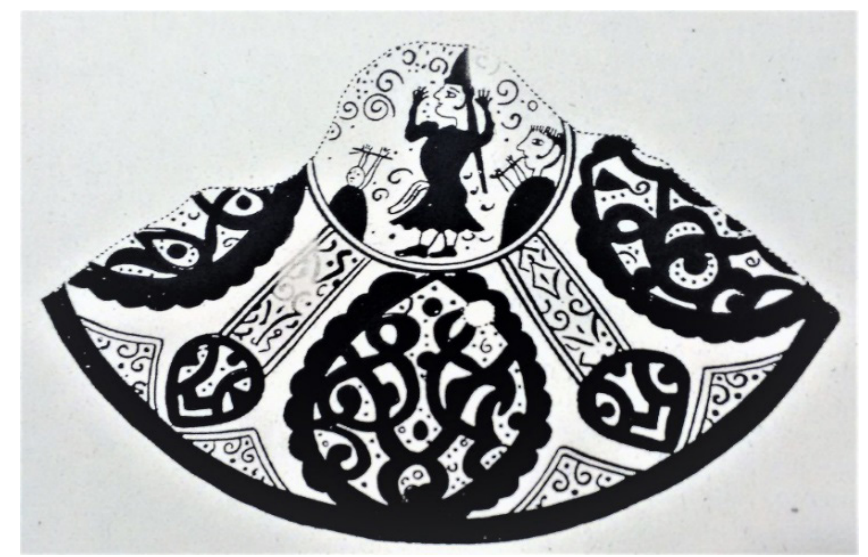

FIG. 4 : Singular ceràmica dels tallers de Manises, primera meitat del segle Xv. El cercle central il lustra una sintètica escena protagonitzada per una ballarina -tal vegada una prostituta- abillada amb un vestit curt, ajustat amb un cinturó, que deixa veure clarament el calçat, uns botins de poca altura. El pentinat piramidal està rematat amb una mantellina o una trena que li arriba al nivell de la cintura. És peculiar el prominent rínxol que estilitza uns trets facials molt esquemàtics. La ballarina té els braços en alt i una actitud corèutica molt diferent de la de les dansaires cortesanes de la producció valenciana en verd i manganés. L’acompanya un joglar que fa sonar una espècie de flauta o oboè amb una terminació lleugerament sinuosa. El músic llueix els cabells en punta i el mateix rínxol que la ballarina. El tercer personatge, fet amb traços naïs, té el cap completament pelat i sembla que realitza uns exercicis malabars o, tal vegada, dirigeix el ball amb un bastó [Londres, British Museum; infografia realitzada a partir de González Martí (1944: 416, fig. 513)]. 
Raül Sanchis Francés. Connexions entre el ball i la prostitució en la tardor medieval: fembres pecadrius, reis arlots i çabies

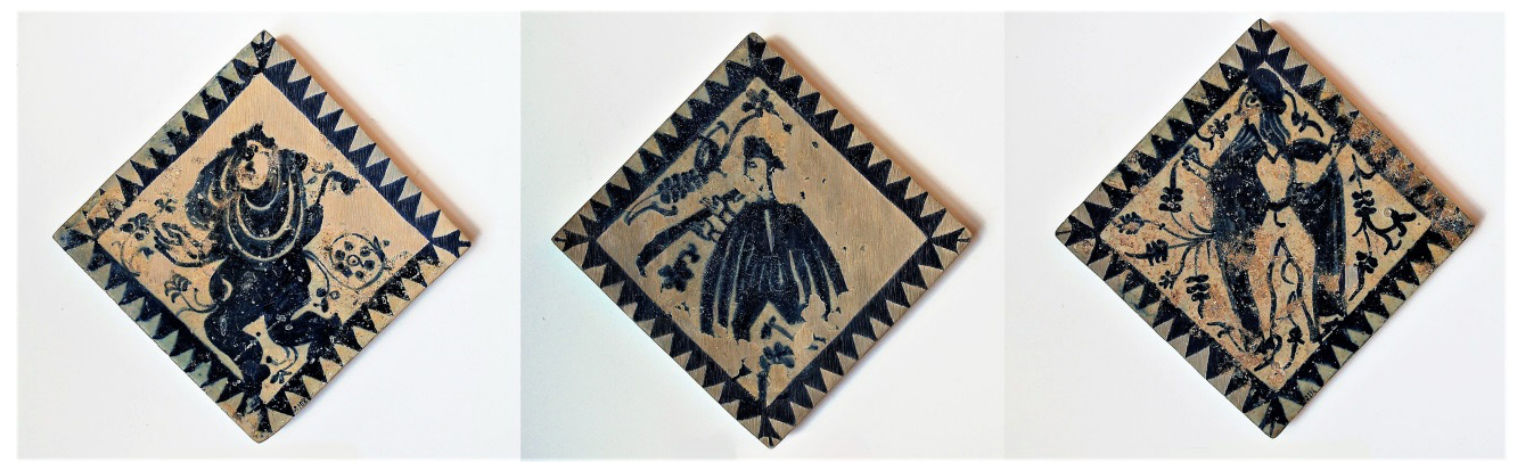

FIG. 5: Rajoles del palau dels Boil procedents dels tallers de Manises, mitjan s. Xv. Ceràmiques ornamentals de la sèrie blava orlades amb puntes de serra. D'esquerra a dreta: figura femenina amb vestidures d'estil morisc que mostra una actitud corèutica, músic amb un instrument de vent lleugerament cònic, i donzell amb posat corèutic [València, Museu Nacional de Ceràmica i Arts Sumptuàries González Martí, núm. inv. CE1/02108, CE1/02109 i CE1/02112; fotografies: Ana Grau].

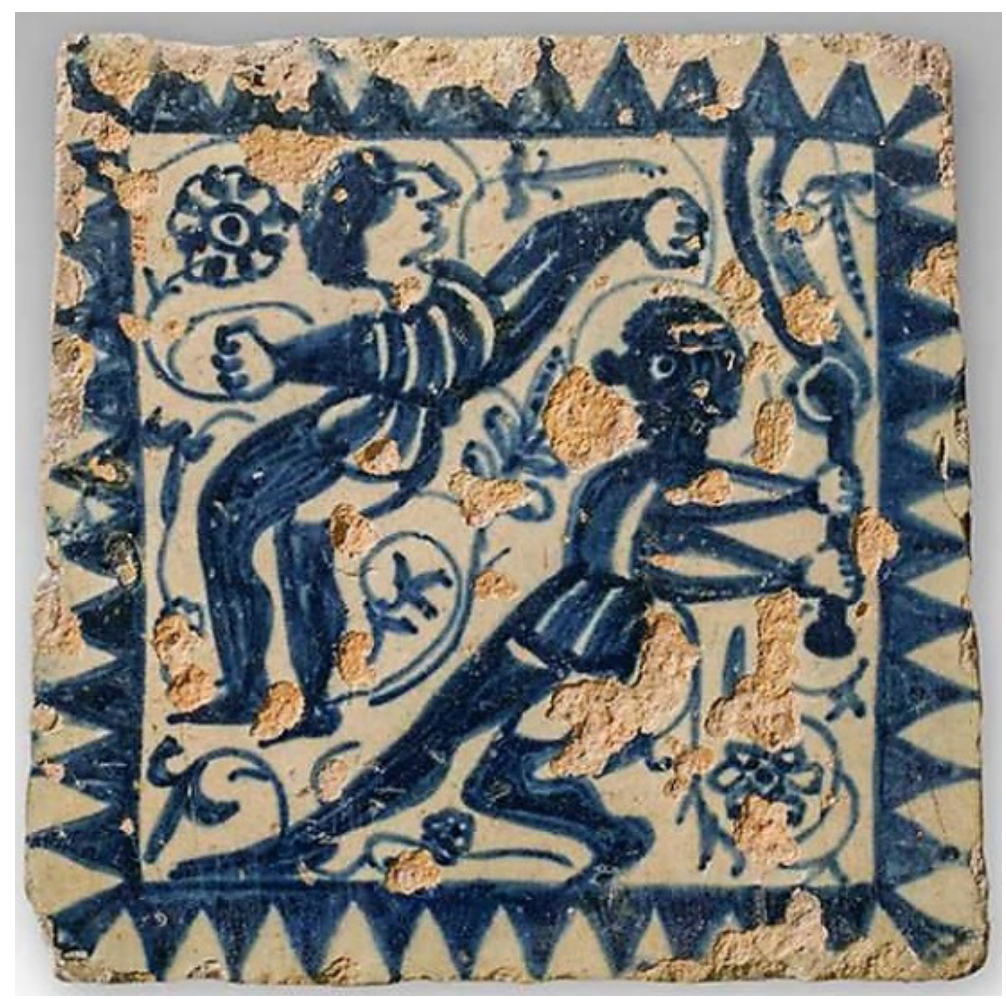

Fig. 6: Joglars fent funambulismes. L'acròbata amb el rostre negre (segurament morisc) sembla que llance el seu company perquè faça equilibris. Rajola en blau i blanc de la sèrie de puntes de serra, procedent del palau dels Boïl de Manises, darrer quart del segle XV [Barcelona, Museu del Disseny, núm. reg. MCB 52152; fotografia: Guillem Fernández-Huerta].

SCRIPTA, Revista internacional de literatura i cultura medieval i moderna, núm. 16 / desembre 2020 / pp. $300-319$ ISSN: 2340-4841 · doi:10.7203/SCRIPTA.16.19232 
Raül Sanchis Francés. Connexions entre el ball i la prostitució en la tardor medieval: fembres pecadrius, reis arlots i çabies

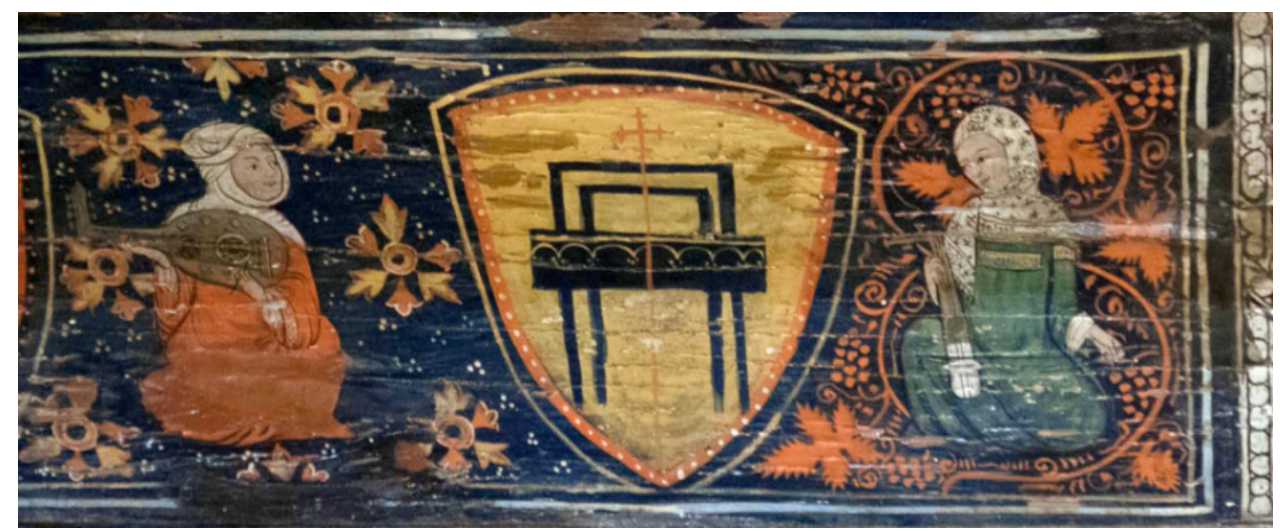

Fig. 7: Al sostre de la sala del tresor de la catedral de Tarragona s'han conservat unes pintures gòtiques del segle XIV (c. 1355-1360) que originalment havien format part d'una tribuna que sostenia un cor de fusta. Intercalades amb els escuts heràldics del capítol tarragoní i dels arquebisbes fra Sancho López de Ayerbe i Pere de Clasquerí, hi ressalten algunes imatges de contingut coreomusical. És notable el caràcter islamitzant del conjunt amb motius cal ligràfics d'inspiració cúfica. En la imatge que hem seleccionat, s'aprecien dues joglaresses sarraïnes que fan sonar un llaüt i un rabec, amb el plectre i l'arc a la mà esquerra [fotografia: cortesia de Licia Buttà]. 